\title{
ИССЛЕДОВАНИЕ ПЕРЕРАБОТКИ ФОСФОРИТОВ МЕСТОРОЖДЕНИЯ АЗЕРИ В ДВОЙНОЙ СУПЕРФОСФАТ
}

Месторождение фосфоритов Азери располагается в северо-восточной части Эстонской ССР, восточнее месторождения Тоолсе; переработка концентратов последнего исследована ранее [1-4]. Фосфориты обоих месторождений содержат относительно много пирита, а фосфориты Азери отличаются еще и высоким содержанием доломита, поэтому они среди изученных фосфоритов Прибалтийского бассейна наиболее сложны как объект химической переработки.

Таблица 1

Характеристика использованных фосфоритных концентратов

\begin{tabular}{|c|c|c|c|c|c|c|c|}
\hline \multirow{2}{*}{ Показатели } & \multicolumn{7}{|c|}{ Номер образца фосконцентрата } \\
\hline & 1 & 2 & 3 & 4 & 5 & 6 & 7 \\
\hline $\begin{array}{l}\text { Содержание, \% } \\
\mathrm{P}_{2} \mathrm{O}_{5} \\
\mathrm{CaO} \\
\mathrm{MgO} \\
\mathrm{Fe}_{2} \mathrm{O}_{3} \text { общий }\end{array}$ & $\begin{array}{c}23,5 \\
39,4 \\
3,86 \\
3,97\end{array}$ & $\begin{array}{c}24,3 \\
39,8 \\
3,14 \\
4,06\end{array}$ & $\begin{array}{l}25,9 \\
40,9 \\
2,56 \\
4,57\end{array}$ & $\begin{array}{c}26,0 \\
39,5 \\
1,85 \\
4,85\end{array}$ & $\begin{array}{l}29,0 \\
44,0 \\
2,72 \\
2,72\end{array}$ & $\begin{array}{c}29,4 \\
47,4 \\
3,89 \\
2,43\end{array}$ & $\begin{array}{c}30,1 \\
47,9 \\
3,80 \\
1,47\end{array}$ \\
\hline $\begin{array}{l}\text { в том числе } \\
\mathrm{Fe}_{2} \mathrm{O}_{3} \text { непиритный } \\
\mathrm{Fe}_{2} \mathrm{O}_{3} \text { пиритный } \\
\mathrm{R}_{2} \mathrm{O}_{3} \\
\mathrm{~F} \\
\mathrm{CO}_{2} \\
\mathrm{SO}_{3} \text { общий }\end{array}$ & $\begin{array}{l}1,37 \\
2,60 \\
4,19 \\
2,76 \\
7,97 \\
5,81\end{array}$ & $\begin{array}{l}1,01 \\
3,05 \\
4,45 \\
3,02 \\
7,10 \\
6,43\end{array}$ & $\begin{array}{l}0,97 \\
3,60 \\
4,97 \\
2,97 \\
5,23 \\
7,67\end{array}$ & $\begin{array}{l}1,10 \\
3,75 \\
5,22 \\
3,30 \\
5,06 \\
8,09\end{array}$ & $\begin{array}{l}0,89 \\
1,83 \\
2,82 \\
2,98 \\
5,56 \\
4,19\end{array}$ & $\begin{array}{l}1,07 \\
1,36 \\
2,61 \\
2,96 \\
8,51 \\
3,24\end{array}$ & $\begin{array}{c}1,28 \\
0,19 \\
1,72 \\
2,86 \\
8,66 \\
0,82\end{array}$ \\
\hline $\begin{array}{l}\text { в том числе } \\
\mathrm{SO}_{3} \text { сульфатный } \\
\mathrm{SO}_{3} \text { пиритный } \\
\text { Нерастворимый остаток }\end{array}$ & $\begin{array}{c}0,59 \\
5,22 \\
12,4\end{array}$ & $\begin{array}{c}0,32 \\
6,11 \\
14,3\end{array}$ & $\begin{array}{c}0,46 \\
7,21 \\
13,2\end{array}$ & $\begin{array}{c}0,57 \\
7,52 \\
14,6\end{array}$ & $\begin{array}{l}0,53 \\
3,66 \\
8,7\end{array}$ & $\begin{array}{l}0,52 \\
2,72 \\
0,6\end{array}$ & $\begin{array}{l}0,44 \\
0,38 \\
1,6\end{array}$ \\
\hline $\begin{array}{l}\text { Соотношение масс } \\
\mathrm{CaO}: \mathrm{P}_{2} \mathrm{O}_{5} \\
\mathrm{MgO}: \mathrm{P}_{2} \mathrm{O}_{5} \\
\text { Общий } \mathrm{Fe}_{2} \mathrm{O}_{3}: \mathrm{P}_{2} \mathrm{O}_{5}\end{array}$ & $\begin{array}{l}1,67 \\
0,164 \\
0,169\end{array}$ & $\begin{array}{l}1,64 \\
0,129 \\
0,167\end{array}$ & $\begin{array}{l}1,58 \\
0,099 \\
0,176\end{array}$ & $\begin{array}{l}1,52 \\
0,071 \\
0,186\end{array}$ & $\begin{array}{l}1,52 \\
0,094 \\
0,094\end{array}$ & $\begin{array}{l}1,61 \\
0,132 \\
0,083\end{array}$ & $\begin{array}{l}1,59 \\
0,126 \\
0,049\end{array}$ \\
\hline $\begin{array}{l}\text { в том числе } \\
\text { непиритный } \mathrm{Fe}_{2} \mathrm{O}_{3}: \mathrm{P}_{2} \mathrm{O}_{5} \\
\text { пиритный } \mathrm{Fe}_{2} \mathrm{O}_{3}: \mathrm{P}_{2} \mathrm{O}_{5}\end{array}$ & $\begin{array}{l}0,058 \\
0,111\end{array}$ & $\begin{array}{l}0,041 \\
0,126\end{array}$ & $\begin{array}{l}0,037 \\
0,139\end{array}$ & $\begin{array}{l}0,042 \\
0,144\end{array}$ & $\begin{array}{l}0,031 \\
0,063\end{array}$ & $\begin{array}{l}0,036 \\
0,047\end{array}$ & $\begin{array}{l}0,042 \\
0,007\end{array}$ \\
\hline $\begin{array}{l}\text { Содержание фракции, \% } \\
+0,18 \text { м. } \\
(-0,18)-(+0,071) \text { м. } \\
-0,071 \text { м. }\end{array}$ & $\begin{array}{r}5,2 \\
43,0 \\
51,8\end{array}$ & $\begin{array}{r}8,6 \\
69,2 \\
22,2\end{array}$ & $\begin{array}{r}7,4 \\
66,0 \\
26,6\end{array}$ & $\begin{array}{r}5,4 \\
52,6 \\
42,0\end{array}$ & $\begin{array}{r}6,6 \\
71,2 \\
22,2\end{array}$ & $\begin{array}{r}6,8 \\
73,0 \\
20,2\end{array}$ & $\begin{array}{r}26,8 \\
65,8 \\
7,4\end{array}$ \\
\hline
\end{tabular}


В настоящей статье приводятся результаты лабораторного исследования по переработке фосфоритов Азери в двойной суперфосфат (ДС). Использовались 7 образцов флотоконцентратов (табл. 1), полученных в Научно-исследовательском институте горно-химического сырья по анионной (обр. 1-4) и анионно-катионной (обр. 5-7) схемам флотации. Концентраты различаются по содержанию как полезного компонента $\left(\mathrm{P}_{2} \mathrm{O}_{5}\right)$, так и примесей (нерастворимый остаток, магний- и железосодержащие минералы и др.). Магний представлен в основном легкорастворимым доломитом, растворимость железосодержащих минералов различна. С точки зрения растворимости аналитически определяемое содержание общего железа можно разделить на: 1) непиритное железо, растворимое в минеральных кислотах, и 2) пиритное железо, растворимое только в кислотах-окислителях, например, в азотной кислоте. В фосконцентратах Азери содержание пиритного железа колеблется в широком диапазоне, максимальное - $3,75 \%$ (в пересчете на $\mathrm{Fe}_{2} \mathrm{O}_{3}$ ), а содержание непиритного железа относительно ровное и не превышает $1,4 \%$. Обогащением руды до содержания $\mathrm{P}_{2} \mathrm{O}_{5}$ свыше $30 \%$ достигается практически полное удаление пиритного железа из концентрата.

Переработка фосфоритов Азери в ДС осуществлялась тремя способами: классическим камерным, бескамерно-поточным и камерно-поточным. Использовались фосконцентраты тонкого помола, содержащие около $20 \%$ фракции $+0,071$ мм.* Разложение фоссырья проводилось экстракционной фосфорной кислотой (ЭФК), полученной из кольского апатитового концентрата. Количество ЭФК принималось равным стехиометрической норме для получения ДС с учетом содержания $\mathrm{CaO}, \mathrm{P}_{2} \mathrm{O}_{5}$, $\mathrm{Fe}_{2} \mathrm{O}_{3}$ и $\mathrm{MgO}$ в фосфорите и первого водородного иона в кислоте. ЭФК содержала, \%: $\mathrm{P}_{2} \mathrm{O}_{5} \quad 30,5(48,4-49,3) * * ; \mathrm{SO}_{3} 1,6 \quad(2,5-2,9) ; \mathrm{Fe}_{2} \mathrm{O}_{3} \quad 0,4$ $(0,6-0,8) ; \mathrm{H}^{+}-$иона $0,52(0,74-0,75)$. При дозировании фосфорита в реактор добавлялся пеногаситель - изоамиловый спирт. Нейтрализация продуктов при камерном и бескамерно-поточном способах производилась техническим мелом, при камерно-поточном - газообразным аммиаком. Методика экспериментов более подробно описана в $[5,6]$, методика анализа фоссырья и образцов ДС - в [7].

К а м е ны й способ. Из результатов исследования (табл. 2) следует, что из всех образцов фосконцентрата были получены образцы ДС, отвечающие требованиям ГОСТ 16 306-75 марки «Б» (содержание усвояемого $\mathrm{P}_{2} \mathrm{O}_{5}$ не менее $42 \%$ ). Физические свойства продуктов удовлетворительны. Однако в зависимости от состава исходного фосфорита наблюдались различия в показателях процесса. Камерный ДС содержал (в \%) 11,5 - 13 свободного $\mathrm{P}_{2} \mathrm{O}_{5}$ и до 12 влаги при степени разложения фосфорита $\left(\mathrm{K}_{\mathrm{p}}\right) 61-74 \%$, а дозревший в течение $9-12$ сут продукт $-7-9,5$ свободного $\mathrm{P}_{2} \mathrm{O}_{5}$ и 8-11 влаги при еще более широком диапазоне колебаний $\mathrm{K}_{\mathrm{p}}(74-96 \%)$. Наибольшее доразложени́е фосфорита при дозревании (рис. 1) пронсходило в опытах с применением фосфоритных концентратов 3,5 и 6 , имевших, по сравнению с другими пробами, более низкое содержание растворимых соединений железа и алюминия. При этом повышение $\mathrm{K}_{\mathrm{p}}$ при дозревании проб ДС прямо пропорционально мольному отношению содержания полуторных оксидов $\left(\mathrm{Fe}_{2} \mathrm{O}_{3}+\mathrm{Al}_{2} \mathrm{O}_{3}\right)$ к содержанию $\mathrm{P}_{2} \mathrm{O}_{5}$.

В стадиях дообработки ДС (нейтрализация, гранулирование и суш-

* При камерном способе была проверена также возможность применения фосфорита стандартной тонины помола (ГОСТ 5716-74), однако такое сырье оказалось непригодным из-за неудовлетворительных физико-химических свойств камерного ДС.

** В скобках даны показатели проб упаренной кислоты. 
Результаты экспериментов получения ДС

\begin{tabular}{c|c|c|c|c|c|c|c}
\hline \multirow{2}{*}{ Показатели } & \multicolumn{6}{|c}{ Номер образца фосконцентрата } \\
\cline { 2 - 7 } & 1 & 2 & 3 & 4 & 5 & 6 & 7 \\
\hline
\end{tabular}

\section{Камерный способ получения ДС}

Коэффициент разложения фосфорита, $\%$

\begin{tabular}{lrrrrrrr} 
в камерном продукте & 64,1 & 61,0 & 73,9 & 66,9 & 71,2 & 69,4 & 63,6 \\
в вызревшем продукте & 76,7 & 74,8 & 87,8 & 82,5 & 95,8 & 91,4 & 79,6 \\
в нейтрализованном продукте & 77,0 & 72,5 & 85,7 & 81,5 & 86,1 & 84,1 & 81,4 \\
Продолжительность вызревания, сут & 10 & 10 & \multicolumn{1}{c}{9} & 10 & 10 & 11 & 10 \\
Содержание в нейтрализованном про- & & & & & & & \\
дукте, \% & & & & & & & \\
общий $\mathrm{P}_{2} \mathrm{O}_{5}$ & 46,4 & 45,9 & 45,9 & 46,6 & 48,2 & 49,0 & 49,6 \\
усвояемый $\mathrm{P}_{2} \mathrm{O}_{5}$ & 44,0 & 43,0 & 44,3 & 44,5 & 46,5 & 47,2 & 47,4 \\
водорастворимый $\mathrm{P}_{2} \mathrm{O}_{5}$ & 42,3 & 42,2 & 42,6 & 43,1 & 44,6 & 45,5 & 45,7 \\
свободный $\mathrm{P}_{2} \mathrm{O}_{5}$ & 1,8 & 3,5 & 3,1 & 2,1 & 3,5 & 3,7 & 4,2 \\
влага & 3,5 & 3,6 & 4,0 & 2,0 & 3,4 & 5,3 & 4,6
\end{tabular}

Бескамерно-поточный способ получения ДС

Коэффициент разложения фосфори-

та, \%

$\begin{array}{lrrrrrrr}\text { В сухом продукте } & 61,8 & 61,2 & 70,7 & 70,8 & 69,0 & 65,1 & 69,8 \\ \text { в нейтрализованном продукте } & 60,9 & 61,4 & 69,1 & 71,4 & 70,6 & 65,3 & 70,1 \\ \begin{array}{l}\text { одержание в нейтрализованном про- } \\ \text { дукте, \% }\end{array} & & & & & & \\ \text { общий } \mathrm{P}_{2} \mathrm{O}_{5} & 46,0 & 45,5 & 46,1 & 45,1 & 47,9 & 49,2 & 49,1 \\ \text { усвояемый } \mathrm{P}_{2} \mathrm{O}_{5} & 41,8 & 41,2 & 42,4 & 41,7 & 44,1 & 44,9 & 45,3 \\ \text { водорастворимый } \mathrm{P}_{2} \mathrm{O}_{5} & 40,6 & 40,5 & 41,1 & 40,6 & 42,9 & 43,7 & 44,2 \\ \text { свободный } \mathrm{P}_{2} \mathrm{O}_{5} & 4,4 & 5,1 & 5,4 & 4,7 & 5,4 & 5,6 & 6,2 \\ \text { влага } & 5,7 & 5,9 & 4,1 & 4,3 & 5,1 & 5,7 & 5,7\end{array}$

Камерно-поточный способ получения ДС

Коэффициент разложения фосфори-

та, \%

$\begin{array}{llllllll}\text { в камерном продукте } & - & - & 74,4 & 63,3 & 61,8 & \text { - } \\ \text { в сухом продукте } & - & - & 76,5 & 67,0 & 67,5 & \text { - } & \text { - } \\ \text { в нейтрализованном продукте } & - & - & 72,1 & 69,6 & 67,8 & - & - \\ \text { одержанне в нейтрализованном про- } \\ \text { укте, \% }\end{array}$

ка) в большинстве опытов происходила ретроградация усвояемого $\mathrm{P}_{2} \mathrm{O}_{5}$. Она была наиболее значительной в тех случаях, когда $\mathrm{K}_{\mathrm{p}}$ в дозревшем ДС превышал $90 \%$. В гранулированном высушенном продукте $\mathrm{K}_{\mathrm{p}}$ составлял $72-86 \%$.

Влияние изменений качества сырья и некоторых технологических показателей процесса на содержание усвояемого $\mathrm{P}_{2} \mathrm{O}_{5}$ в продукте характеризуют данные табл. 3. При учете этих зависимостей возможно в некоторой степени регулировать качество продукта.

Анализ полученных экспериментальных данных (рис. 2) позволяет конкретизировать зависимость $\mathrm{K}_{\mathrm{p}}$ фоссырья от содержания в нем основ- 


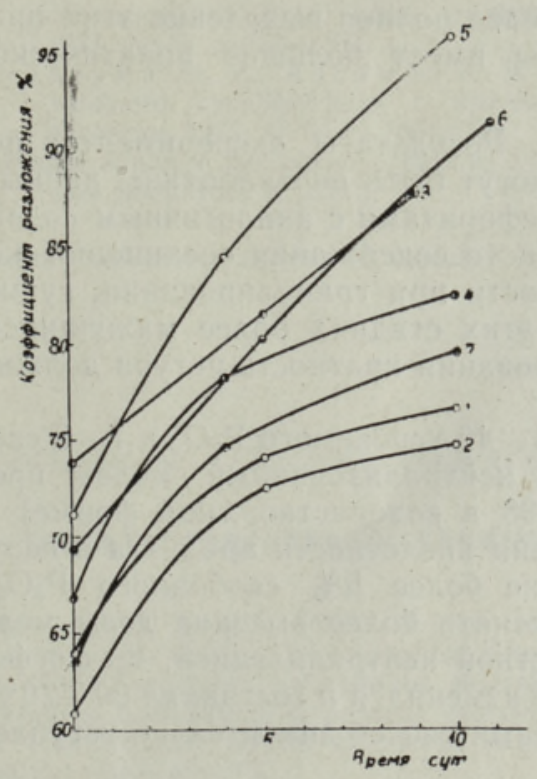

Рис. 1. Зависимость коэффициента разложения фосфорита в пробах ДС от продолжительности дозревания. $1-7$ - номера фосконцентрата по табл. 1

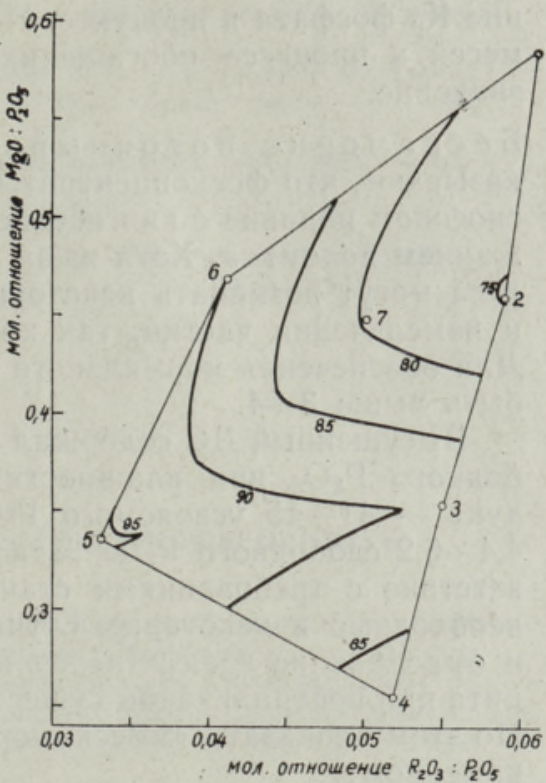

Рис. 2. Зависимость коэффициента разложения фосфорита в пробах дозревшего ДС от содержания примесей в исходном фосконцентрате. $1-7-$ номера фосконцентратов по табл. $1 ; 75,80$, $85,90,95$ - коэффициенты разложения, \%.

ных растворимых примесей - алюминий-, железо-и магнийсодержащих минералов. Увеличение содержания полуторных оксидов $\left(\mathrm{Al}_{2} \mathrm{O}_{3}+\mathrm{Fe}_{2} \mathrm{O}_{3}\right)$ ухудшает разложение фосфата. Влияние же магнийсодержащих примесей $(\mathrm{MgO})$ более сложно, но в основном диапазоне варьирования их содержания увеличение соотношения $\mathrm{MgO}: \mathrm{P}_{2} \mathrm{O}_{5}$ также вызывает сниже-

Таблица 3

Основные факторы, влияющие на содержание усвояемого $\mathrm{P}_{2} \mathrm{O}_{5}$

\begin{tabular}{l|c|c}
\hline Факторы процесса & $\begin{array}{c}\text { Изменение } \\
\text { факторов } \\
\text { процесса, \% }\end{array}$ & $\begin{array}{c}\text { Изменение содержа- } \\
\text { ния усвояемого } \mathrm{P}_{2} \mathrm{O}_{5}, \\
\text { абс. \% }\end{array}$ \\
\hline
\end{tabular}

Составные части фосконцентрата

$$
\begin{aligned}
& \mathrm{P}_{2} \mathrm{O}_{5} \\
& \mathrm{CO}_{2} \\
& \text { нерастворимый остаток }
\end{aligned}
$$

Соотношение масс $\mathrm{P}_{2} \mathrm{O}_{5}$ в кислоте (ЭФК) и фосфорите

Коэффициент разложения фосфорита

\section{Влажность продукта}

Соотношение масс нейтрализующей добавки (мела) и усвояемого $\mathrm{P}_{2} \mathrm{O}_{5}$ продукта

$$
\begin{array}{ll}
+1,0 & +(0,6-0,7) \\
+1,0 & +(0,18-0,20) \\
-1,0 & +(0,18-0,20) \\
+1,0^{*} & +(0,06-0,10) \\
+1,0 & +0,11 \\
-1,0 & +(0,45-0,51) \\
-1,0^{*} & +(0,21-0,23)
\end{array}
$$

* В отн. \%; во всех других случаях - абс. \%. 
ние $\mathrm{K}_{\mathrm{p}}$ фосфата в продукте. Поэтому более полное выделение этих примесей в процессе обогащения фосруды имеет большое практическое значение.

Б еск а м е но - по точны й способ. Результаты экспериментов показывают, что фосконцентраты Азери могут быть переработаны данным способом наравне с кингисеппскими фосфоритами с аналогичным содержанием доломита. Хотя из-за повышенного содержания соединений железа могут возникать некоторые трудности при гранулировании, сушке и измельчении частиц, так как ДС в этих стадиях более мажущийся. Для обеспечения нормального гранулирования кратность ретура должна быть выше 3-4.

Высушенный ДС содержал (в \%) 41-46 усвояемого $\mathrm{P}_{2} \mathrm{O}_{5}$ и $7-8$ свободного $\mathrm{P}_{2} \mathrm{O}_{5}$ при влажности $4-6$, а нейтрализованный мелом продукт - 41-45 усвояемого $\mathrm{P}_{2} \mathrm{O}_{5}(97-98$ в водорастворимой форме) и $4,4-6,2$ свободного $\mathrm{P}_{2} \mathrm{O}_{5}$. Для приведения кислотности продукта в соответствие с требованиями стандарта (не более $5 \%$ свободного $\mathrm{P}_{2} \mathrm{O}_{5}$ ) необходимо в некоторых случаях применять более высокие дозы мела и омасливание гранул перед поверхностной нейтрализацией. $\mathrm{K}_{\mathrm{p}}$ фосфорита при нейтрализации существенно не изменялся и составлял $60-70 \%$. По этому показателю бескамерно-поточный способ значительно уступает камерному.

К а мерно-поточный способ. Проверен тремя пробами фосконцентратов. Были получены образцы ДС, аналогичные продуктам бескамерно-поточного способа как по составу, так и по степени разложения, отвечающие требованиям ГОСТ 16 306-75. При сушке гранул происходило доразложение фосфорита на $2-6 \%$. При аммонизации гранул. наблюдалась ретроградация водорастворимого $\mathrm{P}_{2} \mathrm{O}_{5}$ на $4-7 \%$ (отн.), а в одном опыте - даже усвояемого $\mathrm{P}_{2} \mathrm{O}_{5}$. Поэтому аммонизацию следует вести до содержания азота не более $2 \%$. При равных показателях по качеству продукта камерно-поточный метод имеет технологические преимущества перед бескамерно-поточным, как менее громоздкий по схеме и аппаратуре.

Из проведенного исследования следует, что флотационные концентраты фосфорита месторождения Азери могут быть использованы для получения ДС стандартного качества при условии тонкого их помола и применении экстракционной фосфорной кислоты из кольского апатитового концентрата. При поточных способах производства содержание $\mathrm{P}_{2} \mathrm{O}_{5}$ в концентрате должно быть не менее $26-27 \%$, а соотношение масс $\mathrm{MgO}: \mathrm{P}_{2} \mathrm{O}_{5}$ и $\mathrm{Fe}_{2} \mathrm{O}_{3}$ (растворимый) : $\mathrm{P}_{2} \mathrm{O}_{5}$ не более, соответственно, 0,10 и 0,05 .

\section{Л И ТЕ Р А Т У Р А}

1. Кармышов В. Ф., Бруцкус Е. Б., Т рубицын а Г. Я. Полуучение двойного суперфосфата из фосфоритов месторождения Тоолсе и экстракционной фосфорной кислоты из апатита (рукоп.). Деп. НИИТЭхим № 309/74.

2. З авертяева Т. И., К армышов В. Ф., Т рубицына Г. Я., Данилен ко Н. К. Исследования по разработке условий получения двойного суперфосфата из фосфоритных концентратов различных месторождений (рукоп.). Деп. ВИНИТИ № 1801-75.

3. Т ока рев Г. И., К лейман С. И., М айоров а А. В. Получение фосфорной кислоты из влажного флотоконцентрата Тоолсе в дигидратном режиме. Фосфор. пром-сть, 1976, № 11 (31), с. $1-4$.

4. А а с а м яэ Э. Э., В е й д е р м а $M$. А. Получение экстракционной фосфорной кислоты и двойного суперфосфата из фосфоритных концентратов месторождения Тоолсе. - Хим. пром-сть, 1978, № 3, с. 193-196.

5. Вейдерм а М. А., А а самяэ Ә. Э., Лутси с Л. Р. Получение двойного 
суперфосфата из эстонских фосфоритов камерным способом. - Хим. пром-сть, 1971 , № 10, c. $750-753$.

6. В е йд е р м а М. А., А а с а м я э Э. Э. Исследование поточного способа получения двойного суперфосфата с применением различных видов сырья. - Хим. пром-сть, 1973, № 10, с. $756-759$.

7. Методы анализа фосфатного сырья, фосфорных и комплексных удобрений, кормовых фосфатов. М., 1975.

Таллинский политехнический институт

Поступила в редакцию

10/XI 1978

E. AASAMAE, M. VEIDERMA, Anne REBANE

\section{TOPELTSUPERFOSFAADI SAAMINE ASERI LEIUKOHA FOSFORIIDIST}

Artikkel käsitleb Aseri fosforiidi-flotatsioonkontsentraatide kasutamist topeltsuperfosfaadi saamiseks kolme erineva tehnoloogilise skeemi järgi, kusjuures fosforiidiproove on lagundatud Koola apatiidist valmistatud ekstraktsioonfosforhappega. Et tehnoloogiline protsess kulgeks normaalselt ja produkt vastaks riikliku standardi nõuetele, on vaja kasutada peent fosforiidijahu, milles massisuhe $\mathrm{MgO}: \mathrm{P}_{2} \mathrm{O}_{5}$ oleks alla $10 \%$ ja massisuhe $\mathrm{Fe}_{2} \mathrm{O}_{3}$ (lahustuv): $\mathrm{P}_{2} \mathrm{O}_{5}$ alla $5 \%$.

E. AASAMÄE, M. VEIDERMA, Anne REBANE

\section{INVESTIGATION OF OBTAINING DOUBLE SUPERPHOSPHATE FROM ASERI PHOSPHORITE}

The obtaining of double superphosphate by three various methods, using flo using flotation concentrates of Aseri phosphorite (Estonian SSR) and wet-process phosphoric acid from Kola apatite, has been studied. Necessity of using finely ground phosphorite is established and limits of contents of iron and magnesium in the phosphorite are given: weight ratio $\mathrm{MgO}: \mathrm{P}_{2} \mathrm{O}_{5}$ and soluble $\mathrm{Fe}_{2} \mathrm{O}_{3}: \mathrm{P}_{2} \mathrm{O}_{5}$ no more than 0.10 and 0.05 , respectively. 